\title{
MICRO-CT EVALUATION OF ADAPTATION AT TOOTH/RESTORATION INTERFACE USING THREE RESIN COMPOSITE RESTORATIONS PLACED WITH DIFFERENT FILLING TECHNIQUES
}

\author{
Ihab M. Moussa* and Mostafa A. Abdellatif**
}

\begin{abstract}
Aim of the study: This study aimed at evaluating the internal adaptation in terms of percentage of contact using micro-CT $(\mu \mathrm{CT})$ for three resin-based composite restorations placed with different filling techniques.

Materials and methods: Three resin-based composites were investigated in this study: Low shrinkage resin-based composite applied incrementally Filtek ${ }^{\mathrm{TM}}$ P90, Bulk-fill resin-based composite Tetric EvoCeram ${ }^{\circledR}$ Bulk Fill and Sonic Fill composite (Kerr corp. USA) packed using Sonic Fill handpiece. Fifteen maxillary $1^{\text {st }}$ premolars were collected. A Class II mesio-occlusodistal cavity was prepared on each tooth. After a matrix was applied, all resin composites were used according to their manufacturers' instructions then light cured. Scanning of the specimens was performed using a $\mu \mathrm{CT}$ machine. The percentage of contact (\%) for each sample was done by measuring the length of restoration margin and dividing it by the entire length cavity walls in gingival, middle and occlusal $\mu \mathrm{CT}$ sections and calculating their average in percentage. Data was collected and statistically analyzed.
\end{abstract}

Results: Percentage of contact of P90 to their cavities' walls was significantly higher than that of TEC BE which was in turn significantly higher than that of SF. There was no significant difference in percentage of contact of $\mathrm{P} 90$ and TEC BF to different parts of their cavities. Percentage of contact of SF was significantly higher in occlusal and middle thirds of their cavities than to the gingival third. Adaptation of P90 to different parts of their cavities was significantly higher than adaptation of SF to the corresponding parts.

Conclusions: Bulk fill TEC BF and SF composites did not improve percentage of contact compared to low shrinkage silorane based incrementally placed $\mathrm{P} 90$ composite. Furthermore, no difference in adaptation of $\mathrm{P} 90$ and TEC BF composites to different parts of cavities, however, adaptation of the SF to the occlusal parts of cavities was much better than to gingival parts.

KEY WORDS: Micro-CT, adaptation, resin composites, filling techniques

Assistant Professor of Dental Materials Science, Biomaterials Department, Faculty of Dentistry, Cairo University affiliated to King Saud University.

** Lecturer of Dental Materials Science, Biomaterials Department, Faculty of Oral and Dental Medicine, Future University in Egypt, FUE. 


\section{INTRODUCTION}

Over many years, resin composite restorations have gained an increasing popularity because of their esthetics and adhesive bonding to tooth structure. However, during polymerization, composite restorations suffer from volumetric shrinkage ranging approximately from 1-6\%. This polymerization shrinkage is accompanied by the development of polymerization stresses at the restoration/tooth interface. These stresses lead to breaking the tight seal at the margins of the restoration, resulting in marginal leakage, marginal discoloration, hypersensitivity, recurrent caries and eventually pulpal damage. As a result, polymerization shrinkage and stresses affects the longevity and clinical success of composite restorations. Several strategies have been developed in an attempt to reduce the amount of shrinkage and stresses. Of these methods were; alterations in the chemistry of the organic matrix, amount of inorganic matrix and the filling techniques. ${ }^{1-10}$

Incremental filling technique is the conventional method of resin composite placement. Its concept is building up the restoration in thin increments of up to $2 \mathrm{~mm}$ thickness. The advantages of this technique are the increased depth of cure and the reduced polymerization shrinkage. However, it is time consuming and requires along chair-side time..$^{3,11,12}$

Recently, the so-called "Bulk-fill" technique has been developed. It depends on filling the cavity with thick layer up to $4 \mathrm{~mm}$. This increase in the depth of cure is a result of modifications in the organic matrix, the amount and type of the fillers and the photo-initiator system. There is an increase in the use of bulk-fill resin composite because its user- friendly, more simplified procedures and less clinical time needed. . $, 3,5,11,12^{2}$

Another innovation in the resin composite filling technique is the Sonic fill, developed by
Kerr, USA. The sonic energy activates the lowviscosity composite and adapts it to the cavity walls, and carving the composite to the final shape while it reaches its final high viscosity. The manufacturer claims reduced working time, reduced polymerization shrinkage and better internal adaptation. $^{5}$

Several methods have been proposed for the evaluation of marginal leakage or the internal adaptation at the resin composite/tooth interface. Dye penetration method is the most commonly used method. It comprises the immersion of the bonded restoration into a dye or tracer such as methelyne blue, rodamine, silver nitrate or radioactive tracer for a period of time. This is followed by the sectioning of the tooth and observation under a microscope. Although this method is very simple it has several drawbacks; the type, size and concentration of the dye and the affinity of the tooth structure to be stained by the dye and the variations in the immersion period between studies, makes the results incomparable. In addition, sectioning of the tooth is a destructive method which precludes any additional testing. Moreover, this is a qualitative subjective method for assessing microleakage using a score system for measuring depth of dye penetration. . $^{4,9,13}$

X-ray micro-computed tomography (microCT) has been recently introduced as an alternative method for evaluating adaptation. Its main advantage is being a non-destructive method, requiring no sectioning of the tooth structure. It allows 3D reconstruction of the entire dental restoration and its surrounding tissues. The various components of the structures are recognized depending on the differences in their ability to weaken the X-ray beam, with the differences being transformed into a array of grey scale values. . $^{1,46-10,13}$

Therefore, the aim of the present study was to evaluate the internal adaptation in terms of percentage of contact using micro-CT for three 
resin-based composite restorations placed with different filling techniques. The null hypothesis was that there will be no difference in the percentage of contact at the restoration/tooth interface for the three composite restorations placed with the incremental, bulk-fill or sonic-fill techniques.

\section{MATERIALS AND METHODS}

\section{Materials}

Three resin-based composites were investigated in this study: low shrinkage resin-based composite applied incrementally Filtek ${ }^{\mathrm{TM}}$ P90, Bulk-fill resinbased composite Tetric EvoCeram ${ }^{\circledR}$ Bulk Fill and Sonic Fill composite (Kerr corp. USA) packed using Sonic Fill handpece. Details of the materials used in the study are given in Table 1 .

\section{Teeth selection, cavity preparation and restora- tion placement:}

Fifteen extracted, caries-free, human maxillary $1^{\text {st }}$ premolars were collected for this study. Teeth were extracted as a part from orthodontic treatment plan. The teeth were cleaned by removing the soft tissues and hard deposits attached to the surface and then kept in saline solution for 24 hours. A Class II mesio-occluso-distal cavity was prepared on each tooth, using a 330 diamond bur (Midwest ${ }^{\circledR}$, Dentsply Professional), mounted on a high-speed handpiece under copious water coolant. The cavity had the gingival margin located approximately $1 \mathrm{~mm}$ coronal to the cemento-enamel junction (CEJ). The depth of the interproximal box was around $8 \mathrm{~mm}$ in the occlusogingival direction and $2 \mathrm{~mm}$ in the mesio-distal direction at the bottom of the box.

TABLE (1) The materials used in the current study.

\begin{tabular}{|c|c|c|c|c|c|c|}
\hline Materials & code & $\begin{array}{l}\text { Mode of } \\
\text { insertion }\end{array}$ & \multicolumn{2}{|l|}{ Composition } & Manufacturer & $\begin{array}{l}\text { Reference of } \\
\text { composition }\end{array}$ \\
\hline Filtek $^{\mathrm{TM}}$ P90 & P90 & Incremental & $\begin{array}{l}\text { - Silorane resin } \\
\text { - Fillers: Quartz filler and Yttrium } \\
\text { fluoride } \\
\text { - Initiator system: camphorquinone } \\
\text { and iodonium salt (donator of } \\
\text { eletrons) } \\
\text { - Stabilizers and pigments }\end{array}$ & $\begin{array}{l}23 \mathrm{wt} \% \\
76 \mathrm{wt} \% \\
0.9 \mathrm{wt} \% \\
0.1-0.15 \mathrm{wt} \%\end{array}$ & 3M ESPE & 14 \\
\hline $\begin{array}{c}\text { Tetric } \\
\text { EvoCeram }{ }^{\circledR} \\
\text { Bulk Fill }\end{array}$ & $\begin{array}{c}\text { TEC } \\
\text { BF }\end{array}$ & Bulk-fill & $\begin{array}{l}\text { - Dimethacrylates } \\
\text { - Prepolymer } \\
\text { - Barium glass filler, Ytterbium tri- } \\
\text { fluoride, Mixed oxide } \\
\text { - Additive, Initiators, Stabilisers, } \\
\text { Pigments }\end{array}$ & $\begin{array}{l}19.7 \mathrm{wt} \% \\
17.0 \mathrm{wt} \% \\
62.5 \mathrm{wt} \% \\
<1.0 \mathrm{wt} \%\end{array}$ & $\begin{array}{c}\text { Ivoclar } \\
\text { Vivadent AG }\end{array}$ & 15 \\
\hline SonicFill & SF & $\begin{array}{l}\text { Sonically } \\
\text { activated }\end{array}$ & $\begin{array}{l}\text { 3-trimethoxysilylpropyl methac- } \\
\text { rylate, ethoxylated bisphenol-A- } \\
\text { dimethacrylate (Bis-EMA), bisphe- } \\
\text { nol-A-bis-(2-hydroxy- 3-methacry- } \\
\text { loxypropyl) ether, triethylenegly- } \\
\text { coldimeth-acrylate (TEGDMA) } \\
\text { - Silicon dioxide, barium glass filler }\end{array}$ & $83.5 \mathrm{wt} \%$ & $\begin{array}{c}\text { Kerr corp, } \\
\text { USA }\end{array}$ & 16 \\
\hline $\begin{array}{c}\text { Scotchbond }^{\mathrm{TM}} \\
\text { Universal } \\
\text { Adhesive }\end{array}$ & & Adhesive & & & & \\
\hline
\end{tabular}


The cavity was about $4 \mathrm{~mm}$ wide bucco-lingually. The depth of the occlusal part of the cavity was $4 \mathrm{~mm}$. All cavities were prepared by the same operator and a periodontal probe was used to verify preparation dimensions during cutting procedures.

The teeth were divided randomly into three groups according to the type of resin-based composite and filling technique $(\mathrm{n}=5 / \mathrm{gp})$. The specific adhesive system (Scotchbond ${ }^{\mathrm{TM}}$ Universal Adhesive - 3M, USA) as it has the highest radiopacity, was used for all of resin-based composite materials used. After a matrix was applied, All resin composite materials were used according to their manufacturers' instructions. In the incremental technique, P90 composite was applied in four increments (each approximately $2.0 \mathrm{~mm}$ thick), and each layer was separately light-cured for 20 seconds using EliparTMS10 LED curing light (3 M ESPE, St. Paul, MN, USA) with an irradiance of $1200 \mathrm{~mW} /$ $\mathrm{cm}^{2}$. After removal of the metal matrix, additional light curing for 20 seconds of the composite material from the buccal and lingual/palatal aspects was performed. In the bulk-fill technique, TEC BF composite was placed in the prepared cavity in a single $4 \mathrm{~mm}$ increment and light-cured only for $10 \mathrm{~s}$ once.

In the sonic fill group, the filler system has a dramatic reaction to the sonic energy applied through the handpiece during placement. This reduces the viscosity of the material up to $84 \%$ creating adaptation similar to a flowable, to ensure intimate adaptation between the composite and bonded surface. SonicFill Handpiece is an airdriven handpiece connected to dental units using a MULTIflex compatible coupling. The recommended operating pressure range was adjusted to be from 3650psi. The dispensing rate was selected by turning the regulating ring at the base of the handpiece. The dispensing rate range 1 through 5 only affects the flow rate of the composite which does not change the composite viscosity. SF composite compule was fitted into the handpiece and the material was used to fill the entire prepared cavities in single increments. Light curing was performed according to the manufacturer's instructions. Thereafter, each restoration was polished by using a polishing cup. The restored teeth were then stored at $37^{\circ} \mathrm{C}$ in distilled water for 24 hours to avoid dehydration before micro CT testing.

\section{Micro-CT ( $\boldsymbol{\mu C T})$ imaging}

Scanning of the specimens was performed using a $\mu$ CT machine (SkyScan microCT scanners, USA). The scanning parameters used were adjusted to be $100 \mathrm{kV}$ of acceleration voltage, $100 \mu \mathrm{A}$ of beam current, a $0.5 \mathrm{~mm} \mathrm{Al}$ filter, $18 \mu \mathrm{m}$ of resolution and $360^{\circ}$ rotation in $0.5^{\circ}$ steps. The total scanning time was approximately $30 \mathrm{~min}$ for each specimen.

\section{Percentage of contact evaluation}

Three $\mu \mathrm{CT}$ sections in each sample were selected; one at the gingival one third, one at the middle one third and one at the occlusal one third. Using Figi ImageJ 1.51n software, the entire tooth cavity walls lengths in a given $\mu \mathrm{CT}$ section were measures (the red lines) and the entire lengths of restoration margins adapted to the cavity walls in this section were also measured (the green lines), Figure 1. The percentage of contact at restoration/ tooth interface in a $\mu \mathrm{CT}$ section was calculated from

Percentage of contact $=$

The total of green line in a $\mu \mathrm{CT}$ section

The total of red lines in this section

$$
\text { X } 100(\%) \text {......................... Equation } 1 .
$$

The gaps were selected according their lower value thresholds compared to higher value thresholds of the enamel, dentin and resin composite restorations at tooth/restorations interface. This concept was adopted by Meleo et al; 2012. ${ }^{17}$ The mean percentage of contact in each sample was calculated from the average of the three $\mu \mathrm{CT}$ sections of each sample. 


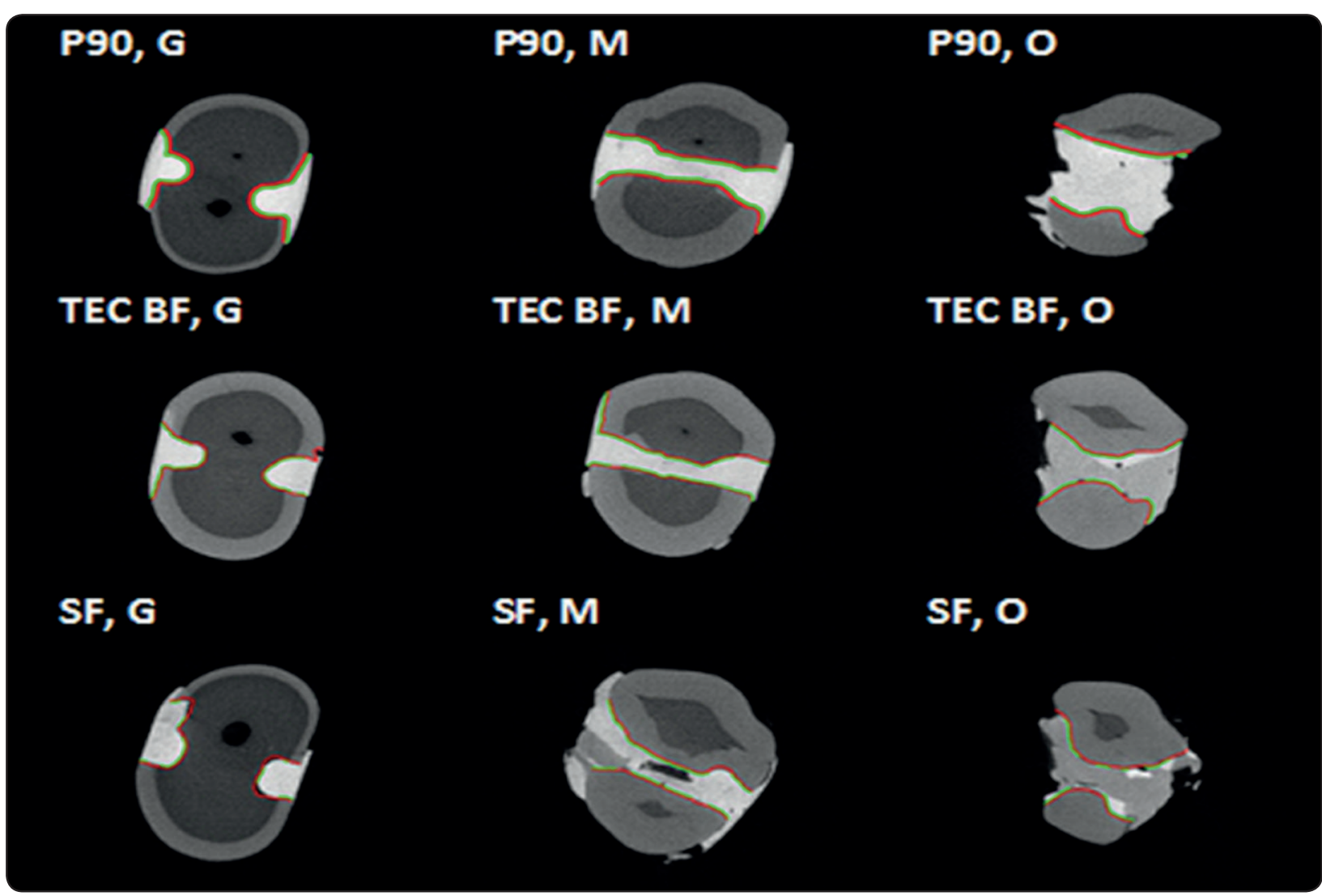

Fig. (1) Micro CT graphs showing samples of sections at different levels of the restorations. The red lines represent the total tooth interface, while the green ones represent the P90, TEC BF and SF composite restorations/tooth interface. The letters G, M and $\mathrm{O}$ represents the gingival, middle and occlusal sections respectively.

\section{Statistical analysis}

Statistical analysis was performed using Statistical Package for Social Sciences, Version 20 (SPSS, Inc., Chicago, III., USA) for Windows. The effects of placement technique on the percentage of contact at tooth/restoration interface were analyzed using one-way analysis of variance (ANOVA). The pairwise comparisons between the three placements techniques were done using Bonferroni post hoc test. $\mathrm{P}$-values $\leq 0.05$ were considered statistically significant.

\section{RESULTS}

Statistical analysis, for the mean and standard deviation values of the percentage of contact for the three placement techniques (incremental, packable bulk fill and sonic fill), is shown in Table 1 and
Figure 1. There was significant difference between the three techniques. The incremental technique using P90 showed the significantly highest mean percentage of contact $(92.38 \pm 11.66 \%)$ followed by the packable bulk fill technique using TEC BF $(79.91 \pm 11.3 \%)$, while the SF showed the lowest percentage of contact at the restoration/tooth interface $(58.97 \pm 12.86 \%)$.

Percentage of contact of differently used composite restorations to different parts of teeth is presented in Table 2 and Figure 2. It was found that no significant differences between adaptation to different parts of teeth in both P90 and TEC BF. On the other hand, percentage of contact of SF to occlusal and middle thirds was significantly higher than to the gingival third. While, comparing percentage of contact of the restorations to same 
thirds of their cavities, it was found that adaptation of P90 to different parts of the cavity was significantly higher that SF adaptation to the corresponding parts of their cavities.

TABLE (2) Mean values and standard deviations (SD) of percentage of contact (\%) for the different restorations at their tooth interface:

\begin{tabular}{|c|c|c|c|}
\hline & & Mean $( \pm$ SD $)$ & $P$ value \\
\hline \multirow{3}{*}{$\begin{array}{l}\text { Filling } \\
\text { Material }\end{array}$} & P90 & $92.38^{\mathrm{a}}( \pm 11.66)$ & \multirow{3}{*}{$<0.05$} \\
\hline & TEC BF & $79.91^{\mathrm{b}}( \pm 11.30)$ & \\
\hline & $\mathrm{SF}$ & $58.97^{\mathrm{c}}( \pm 12.86)$ & \\
\hline
\end{tabular}

Values sharing same letters are statistically insignificant at $\mathbf{P}>0.05$.

\section{DISCUSSION}

Incremental filling technique of resin composite filling materials has been used for decades to optimize composite polymerization adjusting its internal marginal adaptation, using oblique or horizontal $2 \mathrm{~mm}$ thick. ${ }^{11}$ This procedure is believed to reduce the total volumetric shrinkage of the material, the level of the developed polymerization shrinkage, and consequently minimizes internal gap formation. ${ }^{18}$ Yet, placement of the restoration using this technique is complex and significantly timeconsuming.

Recent innovations in dental resin-based restorative materials have resulted in emerging of bulk placement concept, to replace the need

TABLE (3) Relation between filling material and different regions of tooth structure on the percentage of contact at restoration/tooth interface:

\begin{tabular}{|c|c|c|c|c|}
\hline & P90 & TEC BF & SF & \multirow{2}{*}{$\mathrm{P}$ value } \\
\hline & Mean $( \pm$ SD $)$ & Mean $( \pm \mathrm{SD})$ & Mean $( \pm S D)$ & \\
\hline Gingival & $96.38^{\mathrm{aA}}( \pm 4.95)$ & $77.45^{\mathrm{aB}}( \pm 15.34)$ & $45.51^{\mathrm{aC}}( \pm 6.48)$ & $<0.05$ \\
\hline Middle & $93.16^{\mathrm{aA}}( \pm 13.90)$ & $82.15^{\mathrm{aAB}}( \pm 11.76)$ & $71.40^{\mathrm{bB}}( \pm 6.52)$ & $<0.05$ \\
\hline Occlusal & $87.61^{\mathrm{aA}}( \pm 14.46)$ & $80.12^{\mathrm{aA}}( \pm 7.71)$ & $60.00^{\mathrm{bB}}( \pm 8.55)$ & $<0.05$ \\
\hline$P$ value & $>0.05$ & $>0.05$ & $<0.05$ & \\
\hline
\end{tabular}

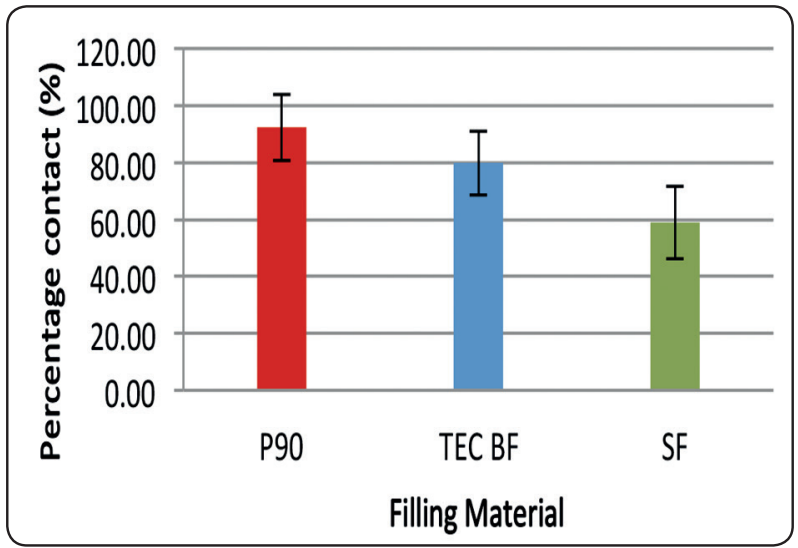

Fig. (2) Means (\%) and standard deviations of the tooth/ composite percentage of contact.

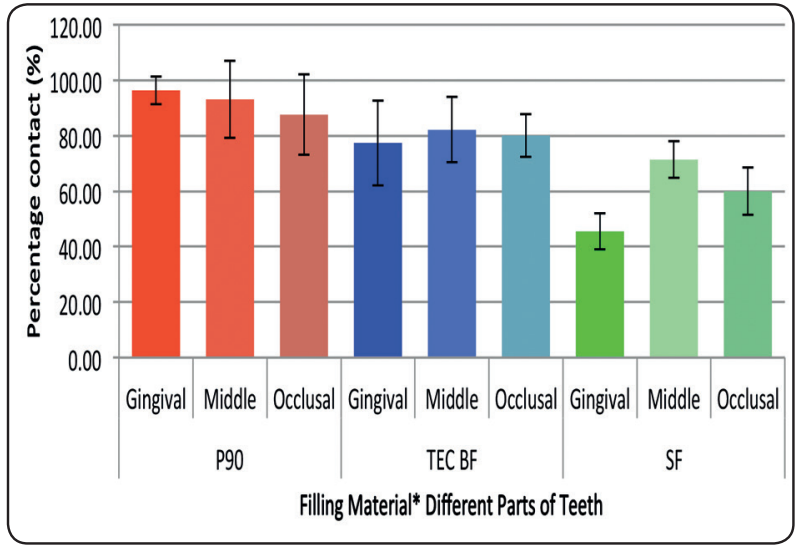

Fig. (3) Means (\%) and standard deviations of the composite percentage of contact to different regions of teeth. 
for incremental layering. ${ }^{19}$ New composites are claimed to display lower polymerization shrinkage and increased curing depth allowing for placement of a single $4 \mathrm{~mm}$ thick increment. This is due to their increased translucency allowing greater light transmission as well as incorporation of special stress relieving monomers with more reactive photoinitiators. ${ }^{20}$ Hence, these composites would simplify the clinical procedures, save time and produce restorations with higher density by minimizing voids incorporation and contamination between composite layers..$^{21,22}$

Many studies have been conducted to study the properties of bulk filled composite restorations. These studies investigated marginal and internal adaptation, depth of curing, polymerization shrinkage and other mechanical properties. ${ }^{3,5,6,16,23}$

Polymerization shrinkage of resin composite inserted into a cavity in natural dentition is affected by many factors including the configuration factor (C-Factor) of the prepared cavity, the efficiency of light curing unit, distance between the curing tip and the surface of restoration, compositional differences between enamel and dentin. However, in the present study, the C-Factor, the curing method, and the bonding system were uniform in all specimens; only the type of resin composite material and placement technique were varied. ${ }^{4}$

X-ray micro-computed tomography $(\mu \mathrm{CT})$ was used to assess the adaptation in terms of percentage of contact at the composite restoration/tooth interface. Micro CT is an effective non-destructive method that can be used in evaluating the internal adaptation of resin-based composite restoration in tooth cavities, from which adaptation and percentage of contact at tooth/restoration interface may be detected..$^{2,8,9}$

Maleo et al; in $2012{ }^{17}$ measured the percentage of contact at tooth/restoration interface using 3D analysis of contact. However, in the current study and due to the huge number of $\mu \mathrm{CT}$ sections in each sample, it was very difficult to convert the $\mu \mathrm{CT}$ sections into 3D models due to limitation of the computer capabilities, and only three $2 \mathrm{D} \mu \mathrm{CT}$ sections were used representing gingival, middle and occlusal thirds for each sample.

The results of our study showed that the incremental technique using P90 showed the significantly highest mean percentage of contact followed by the packable bulk fill technique using TEC BF, while the sonic fill (SF) showed the lowest percentage of contact at the restoration/tooth interface. Therefore, the null hypothesis was totally rejected.

From the important factors that influence polymerization shrinkage of resin composite restorations are the composition of the resin matrix used including the type of the monomer, its monomer molecular weight and percentage. In addition, the concentration, type and size of the filler are also effective. ${ }^{4}$

Despite the recent developments in resin composite materials and placement techniques, the incidence of microleakage is still a common issue. This is due to the polymerization shrinkage of the resin matrix which results in polymerization stress at the restoration/tooth interface. ${ }^{2}$

The highest percentage of contact of P90 could be explained by the fact that P90 is a silorane-based resin composite material. It is mainly composed of a siloxane core and an oxirane ring. Its polymerization occurs via a cationic ring-opening reaction that starts with the generation of an acidic cation that attacks the oxirane ring. The opening of these rings results in volumetric expansion which compensates for the polymerization shrinkage that is responsible for the decreased shrinkage of the P 90. This results in lower polymerization shrinkage compared with those of methacrylate-based resins, which polymerize via addition polymerization reaction. ${ }^{4,24}$

On the other hand, Sonically activated resin composite restorations were supposed to be more promising than traditional bulk fill composites. This is due to the claim that sonic activation of 
such restorations is expected to reduce the viscosity up to $87 \%$, increasing the flow of the composite with better adaptation to cavity walls. Then, after placement, the resin restoration regains its "nonslumping state" that allows for easy contouring. ${ }^{16,21}$ However, the high filler loads of Sonicfill composite $(83.5 \%)$ may require low-molecular-weight monomers (TEGDMA) to ensure a proper handling. In low- viscosity monomers, a high percentage of monomers contribute in the polymerization process due to their active motility, and therefore, increasing the polymerization shrinkage of the Sonicfill. ${ }^{4,16}$ This might support the results of our study where the Sonicfill exhibited the lowest percentage of contact. This goes in accordance with Sun and LinGibson; 2008, that stated that compositions with higher TEGDMA concentration exhibits higher polymerization shrinkage. ${ }^{8}$

However, the results of this study demonstrated that bulk placement of Tetric EvoCeram have resulted in less percentage of contact at the tooth/restoration interface when compared to the incremental placement of $\mathrm{P} 90$. This could be explained by the fact that the lower filler loading of TEC BF (62.5\%) when compared to the filler loading of $\mathrm{P} 90$ (76\%) might have resulted in higher volumetric shrinkage although bulk placement lowers the polymerization stress at the interface due to its placement as one thick increment. ${ }^{2,11}$

Moreover, it is a well-known fact that composite resins with high elastic modulus produce stiffer restorations, which in turn increases the polymerization shrinkage and consequently increases the shrinkage stresses. ${ }^{3}$ According to Leprince et al in 2014, the elastic modulus of P90 was found to be 9GPa, TEC BF was $6.1 \mathrm{GPa}$ and the SF was found to be $8.6 \mathrm{GPa} .{ }^{12}$ However, in the present study, $\mathrm{P} 90$ exhibited the highest percentage of contact at the tooth/restoration interface with the lowest polymerization shrinkage stress, although P90 has the highest elastic modulus. This result might be explained by the fact that P90 is known to have a slow onset taking the longest time to reach the gel point because of the time needed for cation formation. This means that the silorane resin composite possessed the highest potential for stress relief by allowing the resin flow during the initial stage of polymerization. ${ }^{4}$

Regarding the percentage of contact at the different region along the tooth/restoration interface, SF exhibited higher percentage of contact at the occlusal regions compared to the gingival regions. This might be attributed to the high filler content of which decreases composite translucency and in turn reduces the degree of conversion values at the gingival regions of both restorations. This is supported by the fact that both TEC BF and SF are cured as one thick increment, however, this did not occur in P90 due to the incremental packing and curing of each increment. ${ }^{11}$

Furthermore, polymerization shrinkage occurs towards the restoration occlusal surface during light-curing, resulting in composite debonding at the gingival floor. ${ }^{11,23}$

\section{CONCLUSIONS}

Within the limitations of the current study, it can be concluded that bulk fill TEC BF and SF composites did not improve percentage of contact compared to low shrinkage silorane based incrementally placed P90 composite. Furthermore, no difference in adaptation of P90 and TEC BF composites to different parts of cavities, however, adaptation of the SF to the occlusal parts of cavities was much better than to gingival parts.

\section{ACKNOWLEDGMENTS}

The authors would like to thank the College of Dentistry Research Center (CDRC), King Saud University for their precious help in this project. Also, special thanks to Ignacio Tuazon and Lourdez Alegado for their help with the lab work. 


\section{REFERENCES}

1. Han S-H, Sadr A, Tagami J, Park S-H. Non-destructive evaluation of an internal adaptation of resin composite restoration with swept-source optical coherence tomography and micro-CT. Dent Mater. 2016;32(1):e1-e7. doi:10.1016/j.dental.2015.10.009.

2. Han S-H, Sadr A, Tagami J, Park S-H. Internal adaptation of resin composites at two configurations: Influence of polymerization shrinkage and stress. Dent Mater. 2016;32(9):1085-1094. doi:10.1016/j.dental.2016.06.005.

3. Rosatto CMP, Bicalho AA, Veríssimo C, et al. Mechanical properties, shrinkage stress, cuspal strain and fracture resistance of molars restored with bulk-fill composites and incremental filling technique. J Dent. 2015;43(12):15191528. doi:10.1016/j.jdent.2015.09.007.

4. Kim H, Park S. Measurement of the Internal Adaptation of Resin Composites Using Micro-CT and Its Correlation With Polymerization Shrinkage. Oper Dent. 2014;39(2):e57-e70. doi:10.2341/12-378-L.

5. Nainan M, Benjamin S, Swapna M, Koshy S, Kumar A, Nanjappa N. Comparing marginal microleakage of three Bulk Fill composites in Class II cavities using confocal microscope: An in vitro study. J Conserv Dent. 2015;18(5):409-413. doi:10.4103/0972-0707.164058.

6. Rengo C, Spagnuolo G, Ametrano G, et al. Marginal leakage of bulk fill composites in Class II restorations: A microCT and digital microscope analysis. Int J Adhes Adhes. 2015;60:123-129. doi:10.1016/j.ijadhadh.2015.04.007.

7. Carrera CA, Lan C, Escobar-Sanabria D, et al. The use of micro-CT with image segmentation to quantify leakage in dental restorations. Dent Mater. 2015;31(4):382-390. doi:10.1016/j.dental.2015.01.002.

8. Sun J, Lin-Gibson S. X-ray microcomputed tomography for measuring polymerization shrinkage of polymeric dental composites. Dent Mater. 2008;24(2):228-234. doi:10.1016/j.dental.2007.05.001.

9. Sun J, Eidelman N, Lin-Gibson S. 3D mapping of polymerization shrinkage using X-ray micro-computed tomography to predict microleakage. Dent Mater. 2009;25(3):314320. doi:10.1016/j.dental.2008.07.010.

10. Cho E, Sadr A, Inai N, Tagami J. Evaluation of resin composite polymerization by three dimensional micro-CT imaging and nanoindentation. Dent Mater. 2011;27(11):10701078. doi:10.1016/j.dental.2011.07.008.

11. Fronza BM, Rueggeberg FA, Braga RR, et al. Monomer conversion, microhardness, internal marginal adaptation, and shrinkage stress of bulk-fill resin composites.
Dent Mater. 2015;31(12):1542-1551. doi:10.1016/j.dental.2015.10.001.

12. Leprince JG, Palin WM, Vanacker J, Sabbagh J, Devaux J, Leloup G. Physico-mechanical characteristics of commercially available bulk-fill composites. J Dent. 2014;42(8):993-1000. doi:10.1016/j.jdent.2014.05.009.

13. Han S-H, Park S-H. Micro-CT evaluation of internal adaptation in resin fillings with different dentin adhesives. Restor Dent Endod. 2014;39(1):24-31. doi:10.5395/ rde.2014.39.1.24.

14. Filtek ${ }^{\mathrm{TM}}$ P90; Low Shrink Posterior Restorative. 2007. http:// multimedia.3m.com/mws/media/4952900/filtek-p90-technical-profile.pdf. Accessed January 24, 2017.

15. Scientific Documentation Tetric EvoCeram® Bulk Fill. 2014.

16. Ibarra ET, Lien W, Casey J, Dixon SA, Vandewalle KS. Physical properties of a new sonically placed composite resin restorative material. Gen Dent. 2015;63(3):51-56.

17. Meleo D, Manzon L, Pecci R, Zuppante F, Bedini R. A proposal of microtomography evaluation for restoration interface gaps. ANN IST SUPER SANITÀ. 2012;48(1):83-88. doi:10.4415/ANN_12_01_14.

18. Ferracane JL. Resin composite--state of the art. Dent Mater Off Publ Acad Dent Mater. 2011;27(1):29-38. doi:10.1016/j.dental.2010.10.020.

19. Leprince JG, Palin WM, Hadis MA, Devaux J, Leloup G. Progress in dimethacrylate-based dental composite technology and curing efficiency. Dent Mater Off Publ Acad Dent Mater. 2013;29(2):139-156. doi:10.1016/j.dental.2012.11.005.

20. Bucuta S, Ilie N. Light transmittance and micro-mechanical properties of bulk fill vs. conventional resin based composites. Clin Oral Investig. 2014;18(8):1991-2000. doi:10.1007/s00784-013-1177-y.

21. Didem A, Gözde Y, Nurhan Ö. Comparative Mechanical Properties of Bulk-Fill Resins. Open J Compos Mater. 2014;04(02):117-121. doi:10.4236/ojcm.2014.42013.

22. Par M, Gamulin O, Marovic D, Klaric E, Tarle Z. Raman spectroscopic assessment of degree of conversion of bulkfill resin composites--changes at 24 hours post cure. Oper Dent. 2015;40(3):E92-101. doi:10.2341/14-091-L.

23. Park SH, Jung JJ, Han SH. Internal and marginal adaptation of bulk-filled composites. Dent Mater. 2015;31:e17e18. doi:10.1016/j.dental.2015.08.042.

24. Lee I-B, Min S-H, Seo D-G. A new method to measure the polymerization shrinkage kinetics of composites using a particle tracking method with computer vision. Dent Mater. 2012;28(2):212-218. doi:10.1016/j.dental.2011.10.005. 